\title{
TURISMO NA BACIA DO PACÍFICO
}

\author{
Luiz Gonzaga Godoi Trigo ${ }^{1}$
}

\begin{abstract}
RESUMO: A Bacia do Pacífico foi originalmente denominada de "Círculo de Fogo" por geólogos, pois uma série de vulcões e falhas tectônicas se localizam nas bordas deste oceano. Atualmente, o termo é utilizado para denominar um círculo hipotético, que envolve o nordeste e sudeste da Ásia, Austrália, Nova Zelândia e Pacífico Sul e a Costa Oeste das Américas. Neste texto será feita uma análise apenas da costa leste asiática, envolvendo os aspectos econômicos e sua relação com o setor turístico.
\end{abstract}

PALAVRAS-CHAVE: Turismo; Ásia-Pacífico; economia e turismo; qualidade do serviço turístico.

ABSTRACT: "Pacific Rim" was a term used by geologistis to describe the "Ring of Fire" (the chain of volcanoes and earthquake faults) which encircles the Pacific Ocean. Now it has become a term used to describe a circle which encompasses Southeast Asia, Northeast Asia, Australasia and the South Pacific, New Zealand and America's West Coast. In this paper, the analisis will be focused just in the East Coast of Asia, including the economical aspects of the are and its relationship with the tourism industry.

KEY WORDS: Tourism; Pacific RIM; Asia-Pacific; economy and tourism; quality of touristic service.

\section{INTRODUÇÃO}

Os últimos anos da recente história do desenvolvimento econômico internacional foram marcados pela retomada da posição dominante do Japão, especialmente na Ásia Oriental onde, junto com outros

1 Bacharel em Turismo e Filosofia. Mestre em Filosofia Social pela Pontifícia Universidade Católica de Campinas - PUCCAMP. Ex-Diretor de Turismo da PUCCAMP. Professor e Coordenador do Curso de Turismo da PUCCAMP.

End. para corresp.: Rua Major Sólon, 634, apto. 141 - CEP 13091-024 - Campinas -SP-Brasil. 
países em rápido desenvolvimento, tem formado um forte bloco econômico. Esta importância geopolítica e econômica japonesa está inserida em um processo histórico com várias características. A primeira delas é que o Japão beneficiou-se de investimentos norte-americanos, assegurados pelo Plano Colombo ${ }^{2}$, para a Ásia em 1951.

A segunda característica é que o desenvolvimento japonês provocou o crescimento de economias vizinhas como a da Coréia do Sul, Hong Kong, Cingapura e Taiwan (Formosa). Estes quatro países sāo conhecidos por Novos Países Industrializados e pelo cognome de "tigres" ou "dragões" asiáticos, porque "devoram" a economia dos outros países vizinhos. Outros países asiáticos estão igualmente às portas da uma emergência econômica, apesar de possuírem vastas áreas mergulhadas na pobreza, como os arquipélagos da Indonésia e Filipinas, a Malásia e a Tailândia.

A terceira característica envolve outros países como a Rússia, com seu vasto território siberiano debruçado para o Pacífico, China, Austrália e Nova Zelândia. Esses países completam o quadro das nações com influências na região. Boa parte dos problemas regionais se concentram nos países sub-desenvolvidos como Vietña, Laos, Kampuchea e Birmânia, no sudeste asiático, e nas inúmeras e, em geral, paupérrimas ilhas do Pacífico. A Ásia Oriental tem cerca de 280 milhões de pobres e 120 milhões de miseráveis, ao lado da população rica e saudável que vive nas regiões mais desenvolvidas.

Este artigo pretende fazer uma análise histórica do desenvolvimento geral da região do Pacífico e de sua problemática e potencialidade contemporâneas, para poder contextulizar a importância do turismo nestas sociedades pós-industriais com características tão particulares.

\section{ANTECEDENTES HISTÓRICOS E GEOPOLITICA REGIONAL}

O oceano denominado, por Fernão de Magalhães, de "Pacifico" foi, ao longo de sua história, marcado por inúmeros conflitos, que

2 Esse plano, a exemplo do Plano Marshall para a Europa, destinava-se a ajudar e impulsionar a recuperaço do Japão além de, geopoliticamente, manté-lo na esfera de influências dos Estados Unidos graças à ajuda económica. refletem a crescente importância da área. Na Antiguidade e Idade Média, o Mediterrâneo foi o principal eixo de desenvolvimento da humanidade, conforme demonstra o historiador Fernand Braudel. A partir dos séculos XV e XVI, o Atlântico assumiu a posição de principal espaço geográfico de conexão mundial.

Provavelmente, no século XXI, o Pacífico será o mais importante entreposto internacional de transporte, comércio, finanças e turismo. Sua história é marcada por intervenções estrangeiras. Os portugueses começaram a explorar o Extremo Oriente no século XVI e o capitão inglês James Cook terminou de explorar e mapear o oceano entre 1768 e 1779. Mas a hegemonia européia no Pacífico logo começou a sofrer concorrência do expansionismo norte-americano. Já em 1854, o Comodoro Matthew C. Perry atracou sua força naval na baía de Tóquio para garantir o desejo norte-americano de comércio na região. Em 1898, os Estados Unidos tomaram as Filipinas, que pertenciam à Espanha, e ganharam o controle do Havaí, Guam e outras ilhas. A partir da década de 1930 o Japão, entendendo que o Pacífico seria sua área natural de influência, iniciou um expansionismo em direção à Coréia, Mandchúria (nordeste da China), Malásia, Filipinas, Cingapura eoutrasáreas do Sudeste Asiático. A intervenção militar japonesa chegou ao fim em 1945, quandoos Estados Unidos ganharam a Guerra do Pacífico.

O final da Segunda Guerra Mundial não significou a paz. Surgiu a bipolaridade entre os Estados Unidos e a ex-União Soviética, detonando o processo da guerra fria. Neste contexto, a Coréia do Norte invadiu a Coréia do Sul em 1950, provocando duas atitudes diferentes dos Estados Unidos: de um lado a intervenção militar na penísula da Coréia; de outro, a abertura de crédito de bilhões de dólares para patrocinar o desenvolvimento e alinhamento japonês ao mundo capitalista. Tais investimentos tinham por objetivo garantir um "cordão sanitário" para conter o avanço socialista na Ásia. Em 1953, a guerra da Coréia terminou com a manutenção da divisão da península coreana em dois países (Coréia do Norte, socialista; e, Coréia do Sul, capitalista), demarcada por um acordo que fixava como divisa o paralelo $38^{\circ} \mathrm{N}$ e garantida pela presença de $48 \mathrm{mil}$ soldados norte-americanos na fronteira. A situação se manteve permanentemente em uma paz conflituosa e frágil. Em março de 1993, novas tensões, causadas pelo temor de armas nucleares na Coréia do Norte, ameaçavam a paz na penísula coreana. 
Em 1954 começou a surgir outro grande problema. Trop vietnamitas derrotaram os franceses em Dien Bien Phu (Vietña) e houve o início da partilha do Vietña, em plena época de descolonização européia, com observação dos militares norte-americanos. Em 1964, um incidente militar no golfo de Tonquin (Vietña), deu inicio à escalada norte-americana na guerra que durou até 1973. Essa guerra causou a morte de 50 mil soldados americanos e de centenas de milhares de asiáticos, provocando protestos violentos no Ocidente, na década de 1960, e sendo a maior derrota militar dos EUA.

A Rússia e a China têm interesses geopolíticos no Pacífico, fato que preocupa o Japão, recentemente interessado em rearticular suas forças armadas. Desde o final da Segunda Guerra Mundial, o Japão foi proibido pelos Estados Unidos de ter forças armadas convencionais. Apesar de possuir forças policiais bem-equipadas e treinadas, de servir para apoio às manobras norte-americanas na região e de investir em pesquisas bélicas, formalmente o Japão ainda é desmilitarizado.

Em uma época de trocainstantânea de dinheiro e conhecimentos, a bolsa de valores de Tóquio executa mais negócios do que a de Nova Iorque. Nove, dos dez maiores bancos do mundo são japoneses: Mitsubishi, Sumitomo, Dai-Ichi Kangyo, Industrial Bank of Japan, Fuji, Sanwa, Sakura, Bank of Tokio, Long-Term Credit, Takai e Kiowa Saitama (INTERNATIONAL BUSINESS WEEK, 1992: 41).

O iene japonês ajuda a desenvolver os "tigres" asiáticos, apesar das rivalidades históricas. Taiwan e Coréia do Sul, por exemplo, foram ocupados pelo Japão antes da Segunda Guerra Mundial. Após 1945, os interventores norte-americanos promoveram a reforma agrátia nestes países e aumentaram a produtividade agrícola liberando mãode-obra para as atividades industriais. Hoje, Taiwan possui US\$ 84 bilhões de reservas internacionais (mais do que a maioria das economias ocidentais) provenientes dos lucros da exportação de produtos manufaturados. A colônia britânica de Hong Kong e Taiwan canalizam uma imensa quantidade de produtos e negócios para a República Popular da China, especialmente para a província de Guangdong, vizinha a Hong Kong. Desde 1979, essa província é uma Zona Econômica Especial (encrave capitalista autorizado pelo governo) ea cidade de Shenzhen sedia uma das duas Bolsas de Valores da China (a outra situa-se em Xangai). Cantão, capital da província de Gang dong, começa a sediar empresas importantes como o centro de com- putação da empresa aérea Cathay Pacific e outras empresas ligadas à informática.

Nos quatorze anos seguintes após as reformas econômicas de Deng Xiaoping ${ }^{3}$, o PNB da China Continental subiu a uma média de $9 \%$ ao ano, uma taxa que dobra o tamanho da economia a cada oito anos. Se a economia continuar como está, a China deverá crescer a taxas de $10 \%$ ao ano, até o final da década. Se isso acontecer sua economia será, no ano 2000, seis vezes maior do que em 1978. Os atrativos de investimentos estrangeiros para a China são a abertura gradual e controlada do socialismo para a economia de mercado em algumas províncias do litoral oriental, e mais a expectativa de um mercado fabuloso composto por 1,15 bilhão de consumidores potenciais.

\section{DESENVOLVIMENTO DO TURISMO}

A Ásia Oriental faz parte, geograficamente, de uma área conhecida por Bacia do Pacífico ou Ásia-Oceania. Em inglês, recebe o nome de Pacific Rim, que significa, em uma traduação literal, "Aro do Pacífico".

\subsection{O Boom Econômico}

Para que o turismo se desenvolva satisfatoriamente, em um país ou em uma região, é preciso que exista, além do potencial natural ou cultural, estabilidade econômica, política e social. A partir da década de 1950, o crescimentoeconômico foi acontecendo em vários setores da Bacia do Pacífico, convivendo com os vários e violentos conflitos da guerra na Coréia, no Vietña, as convulsões no Laos e Camboja e as ditaduras localizadas, como nas Filipinas. Lentamente, prevaleceu,

3 Deng Xiaoping era um alto dirigente chinês, que em 1976 foi demitido dos postos que exercia, acusado de revisionismo e elitismo. Foi reabilitado em 22/07/1977, após a morte de Mao Tsé-tung. Em 1978 é aprovada uma nova Constituição e nos anos seguintes uma série de medidas econômicas liberalizantes são implementadas, mantendo-se o controle político do país nas mãos do Partido Comunista Chinês, apesar da aprovação de vários encraves capitalistas na China Oriental. 
para a opinião pública mundial, a imagem de paz e progresso no Japão e em alguns outros países. Juntamente com a economia, o turismo floresceu, beneficiando-se do excedente de capital e das peculiares condições de trabalho nos países asiáticos. As economias foram se fortalecendo lenta, mas persistentemente; crescendo com solidez e pragmatismo. As bases foram a indústria, o comércio, as finanças e o turismo.

Jiro Tokuyama, conselheiro do Instituto de Pesquisas Mitsui, no Japão, coordena um estudo interdisciplinar denominado "Os três T: Telecomunicações, Tranporte e Turismo". Esse estudo, patrocinado pela Conferência de Cooperação Econômica do Pacífico, concentra-se nestes três fatores essenciais que serão importantes para acelerar ainda mais o crescimento na região (TOFFLER, 1991:427).

$\mathrm{Na}$ década de 1980, pela primeira vez, o valor dos bens comercializados entre os Estados Unidos e o Pacífico Ocidental excedeu o valor do comércio entre os EUA e a Europa Ocidental. Com um terço da população mundial (5,2 bilhões de habitantes), o comércio asiático vem crescendo rapidamente. Alianças como a Associação das Naçōes do Sudeste Asiático (ASEAN), ajudam nações a se unirem, especialmente nos campos da defesa e do comércio.

O Japão é a principal fonte de crescimento. Sua economia cresceu mais de duas vezes a média mundial até meados da década de 1970, garantida pela exportação de aço, navios, produtos químicos automóveis e produtos eletrônicos. A economia japonesa é forte e flexível, sendo que suas empresas têm uma administração eficiente e estratégicas arrojadas na produção e comercialização de seus produtos no mundo todo, além de acreditarem muito na tecnologia. Entre 1982 e 1986 as companhias japonesas investiram duas vezes mais em informatização das linhas de produção industrial do que as empresas dos EUA. ${ }^{4}$

\subsection{Indicadores Turísticos}

Como conseqüência do grande desenvolvimento econômico de alguns países da Bacia do Pacífico, os indicadores do crescimento

4 Hoje, o Japão é o país com o maior número de robôs insdustriais, em operaçăo, no mundo. quantitativo e qualitativo do turismo, igualmente se alteraram: passaram de uma situação pouco expressiva, até a década de 1970, a uma situação altamente promissora, nos dias atuais, onde a eficiência, o cuidado com os detalhes, a preocupação com novas tecnologias e a qualidade geral dos serviços turísticos do Pacific Rim são reconhecidas em todo o mundo.

Várias publicações têm analisado esta questão. A revista norteamericana Condé Nast Traveler fez uma pesquisa com seus leitores em 1989, 1990, 1991 e 1992, para identificar os cem melhores produtos turísticos do mundo todo, divididos nas seguintes categorias: companhias aéreas, hotéis, resorts (hotéis de lazer), cidades e cruzeiros marítimos (COST NAST TRA VELER, 1989:140; 1990:200; 1991:218; 1992:178).

Em 1989, das dez melhores companhias aéreas internacionais, seiseram do Pacific Rim: Singapore (Cingapura), Qantas (Austrália), Japan Air Lines (Japão), Thai (Tailândia), Air New Zealand (Nova Zelândia) e Cathay Pacific (Hong Kong). Dos dez melhores hotéis, três estavam localizados em Hong Kong e um em Bangcoc (Tailândia).

Em 1990, as mesmas seis companhias aéreas estavam entre as dez melhores. Dos dez melhores hotéis, cinco estavam localizados em Bangcoc (inclusive o primeiro e terceiro lugar - "The Oriental" e "Royal Orchid Sheraton") e Hong Kong. A listagem ainda incluiu os vinte melhores resorts tropicais, estando o Havaí com treze indicaçōes, inclusive os cinco primeiros lugares.

Em 1991 aparecem quatro companhias aéreas do Pacific Rim (Singapore, Thai, Japan Air Lines - JAL - e Qantas) entre as dez melhores; três hotéis entre os dez melhores; e treze resorts tropicais (todos no arquipélogo do Havaí) entre os vinte e três citados.

Em 1992, dos dez melhores hotéis citados, seis estavam situados em Bangcoc e Hong Kong; cinco companhias aéreas (Singapore, JAL, Thai, Qantas e Cathay) estavam entre as dez; e, entre os vinte resorts tropicais, o Havaí continuava liderando a lista com treze referências. Nestes quatro anos da pesquisa, a Singapore Airlines esteve em primeiro lugar na preferência dos milhares de entrevistados. No caso do Havaí, apesar de o arquipélogo pertencer aos Estados Unidos, suas características polinésias e o forte fluxo de turistas do Oriente - 
especialmente do Japão - o colocam bem no centro de influências do Pacífico. ${ }^{5}$

Em termos qualitativos, o número de indicações dos produtos turísticos da Bacia do Pacífico, em diversos segmentos, é bastante siginificativo e considerando-se o desempenho econômico do turismo na região, os números também são impressionantes. As companhias aéreas asiáticas não são as maiores em frota ou em receita. Porém, das onze mais lucrativas empresas internacionais, cinco estão no Pacífico (FLAP INTERNACIONAL, 1992:106):

a) Singapore (1º lugar);

b) Cathay Pacific ( $2^{\circ}$ lugar);

c) Korean (6 lugar);

d) Philippine (9 lugar);

e) Australian (11\% lugar).

Isto significa que, além dessas empresas terem uma elevada qualidade de serviços (atendimento em terra, manutenção, pontualidade, rotas e conexões, serviço de bordo e atenção personalizada aos passageiros), também são eficientes e lucrativas.

O mesmo acontece com a hotelaria. Há quatro grandes companhias hoteleiras asiáticas, ainda não muito conhecidas no Brasil, que se esmeram para garantir aos hóspedes um elevado grau de sofisticação na prestação de serviços. As companhias são a Mandarin Oriental Penísula (criada em 1973), Regent Internacional (principiada em 1970) e Shangri La, o maior grupo da área, criado em 1979 comoparte do holding presidido por Robert Kuok. Existem outros grupos hoteleiros importantes adquiridos pelo capital asiático no final da década de 1980, os quais são: Inter-Continental, Westin e Southern Pacific, igualmente com alto nível de serviços (BESCHER, 1992:577).

Em uma análise quantitativa, os dados continuam a ser promissores. Segundo o WORLD TRAVEL AND TOURISM REVIEW (1991), tomando-se por base os dados de 1989, percebe-se que ofluxo de turismo na Europa está lentamente caindo, apesar de possuir dois

5 É importante ressaltar que, nesta pesquisa da Traveler, não foi incluido nenhum produto turístico da América Latina (exceto México), dos paises africanos, produto turístico da América Latina
islâmicos ou do ex-bloco socialista. rescos das chegadas internacionais e quase metade da receita provenientes do turismo. Ao contrário, o mercado da Ásia-Pacífico está sofrendo um processo de grande expansão no turismo. Nesta região, um grande crescimento econômico é esperado para os próximos vinte anos, a taxas superiores a qualquer outro crescimento das economias capitalistas do planeta. Dos 415 milhões de viajantes internacionais de 1990 , estima-se que 46,5 milhões viajaram para oPacífico. A região possui um terço da população do planeta e produz um quinto do PNB mundial; entretanto, tem apenas $11 \%$ das chegadas turísticas internacionais e $14 \%$ das receitas. Mas o crescimento é acentuado (WORLD TRAVEL AND TOURISM REVIEW, 1991:IX, X).

Em 1988, mais de 300 mil japoneses viajaram para a Austrália e Nova Zelândia, onde o turismo é o fator prepoderante na balança comercial. Desde 1982 o turismo proporcionou mais lucros à Tailândia do que qualquer outra atividade industrial, enquanto que na Indonésia triplicou nesse mesmo período. As novas tendências chegaram até os portos russos de Vladisvostok e Nakhodka, abertos para o turismo, no final da década de 1980 . Com as mudanças na ex-União Soviética, aguarda-se maiores definições governamentais para a continuidade do desenvolvimento turístico nessa região.

Atualmente existem sete países na Ásia que ultrapassam o número de um milhão de viajantes para o Exterior, por ano: Japão, Taiwan, Hong Kong, Malásia, Filipinas, Coréia do Sul e Cingapura. Em 1990, cerca de 12 milhões de japoneses viajaram ao Exterior. Esses sete países superaram a marca de 20 milhões de turistas "exportados". Calcula-se que, até o ano 2000, o total de pessoas que farão viagens internacionais, na região, chegará a 50 milhões, incluídos novos países como a Indonésia, Tailândia e China. Deste total, cerca de 60\% poderão viajar dentro do Pacific Rim (BESCHER, 1992:566).

\section{CONSIDERAÇÕES FINAIS}

Os dados apresentados, inseridos em um contexto de prosperidade e estabilidade razoável, levam analistas como DRUCKER (1991:119) e KENNEDY (1993:6-11), a citar a Bacia do Pacífico como exemplo particular do sucesso conseguido pela economia de mercado, nas difíceis condições sociais e políticas asiáticas. 
As razões do sucesso econômico são apontadas como sendouma mescla de educação formal, trabalho duro, respeito pela autoridad grupal e frugalidade, ou seja, racionalização nas empresas e na vida doméstica para garantir alta qualidade de vida, mas sem desperdício ou gastos exagerados em produtos supérfluos. O nível de poupança familiar no Japão chega a $20 \%$, enquanto que nos EUA é de apenas $5 \%$ em média. Há também fatores como o relacionamento com Ocidente; o acesso ao mercado e às novas tecnologias proporcionado pelos acordos comerciais do após-guerra; e a presença militar norteamericana no Pacífico, garantindo estabilidade nos últimos anos

Em linhas gerais, pode-se agrupar as características das economias "agressivas" dos "tigres", especificamente, em quatro grandes grupos:

a) alta densidade populacional e abundância de mão-de-obra. Fortes restrições ao sindicalismo, Estados altamente centralizados e ditatoriais, apenas recentemente em processo de distensão. Têm uma posição geopolítica estratégica;

b) economias voltadas fundamentalmente para o mercado externo e abertas ao capital estrangeiro;

c) um modelo econômico que enfatiza o equilíbrio social, a consciência de grupo, a disciplina e o nacionalismo. O Estado tem papel importante no planejamento econômico; sua distribuição de renda, apesar dos regimes ditatoriais, é mais equilibrada do que em outros países capitalistas;

d) há grandes estímulos à educação e investimentos na qualificação de mão-de-obra e em novas tecnologias; os índices de analfabetismo se aproximam de zero e a maioria da população termina, no mínimo, o $2^{\circ}$ grau; considerável parcela da população completa os estudos universitários. Estes altos investimentos em educação ocorrem especialmente no Japão e nos "tigres" asiáticos.

A alta qualidade e produtividade asiática, experimentada na agricultura e na indústria, foi igualmente aplicada no setor de serviços, especialmente em transportes, lazer e turismo. Dentro desse contexto, não é de se admirar a inclusão de vários produtos turísticos asiáticos no topo das listas dos melhores serviços internacionais. Com todos estes atrativos, ofluxo de viajantes na Bacia do Pacífico tende a crescer continuamente. Até o início da próxima década o trálego aéreo deve dobrar na região, acarretando problemas de infra-estrutura. Será necessário aumentar o número de aeroportos, vias de acesso, hotéis, resorts e os serviços turísticos de apoio em geral, especialmente para o turismo de negócios.

Enquanto parte das companhias aéreas ocidentais enfrentam crise e prejuízos operacionais, novamente as companhias asiáticas serão, em 1993, as que mais terão lucros. Empresas como Garuda (Indonésia), Korean Air Lines (Coréia do Sul), Malaysian (Malásia) e Taiwan Airlines (Formosa) deverão obter os melhores resultados. A República Popular da China deverá ter um aumento acentuado de tráfego aéreo (THE ECONOMIST, 1992:102).

Finalmente, os investimentos em hotéis, centros de convenções, marketing da região para os países ocidentais e infra-estrutura básica em geral devem se manter elevados. Tudo sempre acompanhado pelas recentes novidades em al ta tecnologia.

Com o aumento de visitantes, é de se esperar que novos destinos turísticos sejam agregados aos já existentes. Inúmeras ilhas e praias desconhecidas da Indonésia, Filipinas e Malásia deverão ser equipadas com confortáveis resorts e facilidades para os turistas. O Vietña tem manifestado interesse em abrir ainda mais suas fronteiras para os negócios e o turismo. À medida que a China continental for sendo desbravada, o mundo terá imensos territórios inéditos para redescobrir.

O cenário da nova ordem internacional (VICENTINO \& SCALZARETTO, 1992), surgido no início desta década, traz em seu bojo uma série de preocupações, angústias e, paradoxalmente, esperanças. É bastante provável que a Bacia do Pacífico mantenha seus índices de crescimento, cristalizando um"bolsão" de prosperidade no cenário mundial, ao lado da América do Norte e da Comunidade Européia. A região pode firmar cada vez mais a imagem de paradigma de eficiência e qualidade, na indústria e no setor terciário. Sendo o turismo uma atividade terciária, e profundamente inserida na problemática internacional, é de se esperar que as transformações e os desdobramentos do processo de desenvolvimento do Pacífico tragam novossubsídios para o setor. Nesse sentido é importante enfatizar o estudo do turismo internacional nessa região.

As características particulares da Ásia interessam ao Ocidente. Há muitas possibilidades de se aprender com suas novas descobertas e projetos. Entender o que acontece do outro lado do planeta ampliará 
os nossos conhecimentos sobre a problemática e a potencialidade do turismo internacional.

\section{BIBLIOGRAFIA}

FLAP INTERNACIONAL. 1992. São Paulo, ano 29, n. 245.

BESCHER, Alexander. 1991. The Pacific Rim Almanac. New York: Harper Perennial.

KENNEDY, Paul. 1993. O Brasil perde corrida para o futuro. Folha de S. Paulo, 21 mar.

DRUCKER, Peter F. 1991. As novas realidades. São Paulo: Pioneiras.

PAYNE, Oliver G. A. M. 1989. Western Pacific Rim Map. Washigton: National Geograpfical Society.

PERALVA, Osvaldo. 1990. Um retrato do Japão. São Paulo: Moderna

CONDÉ NAST TRAVELER. 1989. New York, Nov.

CONDÉ NAST TRAVELER. 1990. New York, Nov.

CONDÉ NAST TRAVELER. 1991. New York, Oct.

CONDE NAST TRAVELER. 1992. New York, Oct.

INTERNATIONAL BUSINESS WEEK. 1992. New York, July.

THE ECONOMIST. 1992. London.

THE WORLD IN 1993. 1992. The Economist. London.

TOFFLER, Alvin. 1991. Powershift. As Mudanças do Poder. Rio de Janeiro: Record.

VICENTINO, C. \& SCALZARETTO, R. 1992. Cenário mundial. A nova ordem internacional. São Paulo: Scipione.

WORLD TRAVEL AND TOURISM REVIEW. 1991. Wallingford: CAB International. v. I

\section{A REVOLUÇÃO DOS TURISTAS ${ }^{1}$}

\section{Francisco Viana ${ }^{2}$}

RESUMO: Oturismo cria a economia de mercado em Cuba e dispara um processo de modernização que a industrialização "ambicionada" pela Revolução não conseguiu fazer. Os negócios, que vivem um verdadeiro "boom" vêm se desenvolvendo com capitais europeus e latino-americanos, mas tendem a alcançar uma dinãmica maior, no Caribe, no caso de uma reaproximação de Cuba com os Estados Unidos.

PALAVRAS-CHAVE: Cuba; desenvolvimento turístico; economia de mercado; empresas turísticas; processo de modernização.

ABSTRACT: The tourism creates a market economy in Cuba and initiates a modernization process that the Revolution was not capable of doing. Business, presently in a "boom" situation, is developing with foreigncapital from Europe and Latin America, but will be in a very previleged situation in The Caribbean if The United States of America begins to help.

KEYWORDS: Cuba: touristic development; market economy; touristic industry; process of modernization.

\section{INTRODUÇÃO}

Duas Cubas, que se comportam como se fossem mundos paralelos, mas estão intimamente interligadas entre si, estão ganhando traços firmes e vivem em choque permanente. Uma é a Cuba de Revolução comunista, fechada para o mundo, onde ninguém sai do país sem ordem do governo, nem há o mínimo vestígio da moderna

1 Artigo que relata a visão do autor sobre o turismo e a economia de mercado em Cuba durante viagem no início de 1993.

2 Jornalista formado pela Universidade Federal da Bahia. Mestre em Comunicação pela Universidade Federal do Rio de Janeiro. Editor da revista Isto $e^{\prime}$ (1981-1993). End. para corresp.: Rua Pará, 90, apto. 131 - CEP 01243-020 - São Paulo SP - Brasil. 